OPEN ACCESS

Edited by:

Cornelia E. Nauen,

Mundus Maris, Belgium

Reviewed by:

Andrés M. Cisneros-Montemayor, Simon Fraser University, Canada

Gorka Merino,

Technology Center Expert in Marine and Food Innovation (AZTI), Spain

*Correspondence:

Owen R. Liu

owen.liu@noaa.gov

tThese authors have contributed equally to this work and share first authorship

Specialty section:

This article was submitted to Marine Fisheries, Aquaculture and

Living Resources,

a section of the journal

Frontiers in Marine Science

Received: 20 January 2021

Accepted: 20 August 2021

Published: 10 September 2021

Citation:

Liu OR and Molina R (2021) The Persistent Transboundary Problem in Marine Natural Resource Management

Front. Mar. Sci. 8:656023.

doi: 10.3389/fmars.2021.656023

\section{The Persistent Transboundary Problem in Marine Natural Resource Management}

\author{
Owen R. Liu ${ }^{1 * t}$ and Renato Molina ${ }^{2,3+}$ \\ ${ }^{1}$ Bren School of Environmental Science and Management, University of California, Santa Barbara, Santa Barbara, CA, \\ United States, ${ }^{2}$ Rosenstiel School of Marine and Atmospheric Science, University of Miami, Miami, FL, United States, ${ }^{3}$ Miami \\ Herbert Business School, University of Miami, Coral Gables, FL, United States
}

Shared natural resources are vulnerable to overexploitation. Countries have established national borders on land and exclusive economic zones (EEZs) in the world's oceans in part to better control exploitation of local resources, but transboundary resources - those that span multiple national jurisdictions - are still subject to incentives for overextraction. We investigate the magnitude and distribution of this "transboundary problem" as it manifests in global fisheries. We show that internationally-shared fisheries exhibit lower relative abundance, on average, than those contained in single EEZs, even in the presence of extraction agreements and modern management practices. Additionally, for the first time we show that the degree of sharing - the number of countries sharing a resource and the spatial balance of each country's share-matters in driving the severity of the transboundary problem. Alleviating the transboundary problem for the fisheries we investigate would result in an estimated 4 to 17 million metric tons more fish in the ocean. In the future, growing human demand and climate change will likely exacerbate pressures on transboundary resources, requiring coordinated international governance solutions.

Keywords: transboundary, fisheries, marine conservation, incentives, spatial analysis

\section{INTRODUCTION}

When natural resources span international boundaries, competitive incentives between nations can result in overextraction (Munro, 1990; Bailey et al., 2010; Hannesson, 2011). Much like the classic tragedy of the commons (Hardin, 2009), as the benefits of resource extraction are enjoyed individually, but the costs of overexploitation are shared collectively, there is little motivation for countries to extract their fair share of a resource that spans multiple national jurisdictions (Barrett, 2003). Countries with access to these transboundary resources have an incentive to capture available economic benefits strategically, and so excessive harvest takes place and the resource becomes overexploited.

In the ocean, the introduction of national exclusive economic zones (EEZs) as part of the UN Convention on the Law of the Sea was meant in part to give countries more control over "their" marine resources (Hannesson, 2011; Nordquist, 2011). The problem is that borders over water lack actual physical obstacles, and hence a variety of jurisdictional arrangements arose: resources can be contained in just one EEZ, span two or more EEZs (i.e., transboundary), migrate between EEZ's and the high seas (known as straddling stocks), or be solely contained in the high seas, outside of any EEZs. Despite the clear limits to access, these marine jurisdictions increased incentives 
for socially inefficient extraction by intensifying competition between incumbents (Schaefer, 1995; Maurihungirire, 2008).

This transboundary resource problem is not unique to the ocean. Managers of internationally-shared natural resources in many ecosystems have struggled to achieve sustainable management. In terrestrial systems, the problem manifests in the difficulties of sharing lake and river water resources, in the threatened status of many migratory species, and in the overexploitation of forest resources across the world (Katerere et al., 2001; Kliot et al., 2001; Sanchez and Roberts, 2014).

The transboundary problem in fisheries will likely worsen in coming years. The number of countries participating in fishing, and the overall number of shared fisheries, have steadily increased during the second half of the twentieth century, creating additional competition for biologically limited resources (Teh and Sumaila, 2015). In addition, climate change is causing species to shift their natural distributions (Pinsky et al., 2013), which exacerbates transboundary issues even further and increases the need for effective international management (Cheung et al., 2012; Pinsky et al., 2018).

These issues have not gone unnoticed, and nations pursue the establishment of multinational commissions and agreements to manage the sharing of valuable transboundary resources. In transboundary forestry management, for example, organizations like the International Tropical Timber Organization have endeavored to promote the sustainable harvesting of timber resources and control the timber trade (Poore, 2003). In the case of fisheries, multilateral efforts such as the Regional Fisheries Management Organizations (RFMOs) for tuna, or South Pacific Regional Fisheries Management Organization for jack mackerel and jumbo squid have been implemented, particularly to manage high-value fish species (Schiffman and MacPhee, 2014; Seto et al., 2021). Another approach has been the implementation of transboundary "peace parks" in both terrestrial and marine systems as an attempt to foster cooperation while contributing to the preservation and sustainable extraction of natural resources (Timothy, 1999; Lysenko et al., 2007; Mackelworth, 2012). Evidence on the effectiveness of these management approaches is mixed (Cullis-Suzuki and Pauly, 2010; Pons et al., 2018).

Recognizing the complexity but increasing urgency of the transboundary issue, this study aims to improve our existing understanding of the problem in a marine setting, as applied to fisheries. Previous research on transboundary marine natural resources has primarily asserted the problem in theoretical terms (Bailey et al., 2010; Munro, 2010; Hannesson, 2011), investigated the performance of management bodies tasked with governing resource extraction (Agrawal, 2001; Cullis-Suzuki and Pauly, 2010; Pons et al., 2018; Seto et al., 2021), or predicted the future effect of climate change on the number of transboundary species (Pinsky et al., 2018). In one empirical study, McWhinnie (2009) showed that the number of countries reporting to exploit a fishery is associated with an increase in the probability of that fishery being classified as "overfished" by the Food and Agriculture Organization of the United Nations (FAO). More recently, Palacios-Abrantes et al. (2020) assessed the revenue garnered from transboundary fisheries, finding that transboundary resources are important economic mainstays for many global nations.

While theoretical studies have predicted that transboundary resources are susceptible to becoming overexploited relative to non-shared resources (Munro, 1990; Hannesson, 2011), and analyses of existing fisheries data have pointed to the economic value of species whose distributions span international borders (Palacios-Abrantes et al., 2020), no studies to our knowledge have brought these two lines of evidence together to specifically identify the magnitude of the effect of transboundary sharing on the expected status of exploited marine species globally. Specifically, we tackle the question: What is the effect of being transboundary on the abundance and odds of overexploitation of marine fisheries resources, relative to non-shared resources? Answering this question provides two contributions that are currently missing in the literature. First, we empirically estimate the effect of international sharing on fish abundance. Second, we show that asymmetric spatial distribution matters when it comes to the transboundary problem - a result that had been previously suggested by economic theory (Hannesson, 2011; Costello and Molina, 2021), but had not been validated. Using these data, we are able to more accurately describe the distribution of the transboundary problem across world regions, as well as estimate total fish abundance attributable to transboundary competition.

Empirical estimation of the transboundary problem requires data on resources that geographically span multiple national jurisdictions, with known conservation and exploitation status. Mindful of this requirement, we utilize a spatially-explicit panel data set that covers approximately half of all globally reported fishery landings, and ask whether there are differences in population size (relative to sustainable levels) between shared and non-shared fish stocks (stocks are demographically self-contained populations of fish species that are defined by fisheries managers). Our theoretical basis (see section 1 in Supplementary Material), building on the work of others (Christy, 1982; McWhinnie, 2009; Munro, 2010; Hannesson, 2011), shows that internationally-shared renewable resources will be exploited to lower levels than those solely owned, even in the presence of altruistic nations. Applied to global fisheries, our expectation is that harvested, transboundary fish stocks have lower relative abundance than their non-shared counterparts, even after controlling for differences in fisheries management such as the presence of international management programs or rights-based fisheries management. We empirically test this expectation using spatially-explicit global data on fisheries status and management programs.

A study of this type comes with several challenges. Most importantly, we need a credible measure of fish stock status that is comparable across diverse stocks. Second, we need to be able to distinguish the transboundary effect for species' distributions that span the high seas-those areas of the ocean outside any country's EEZ-from the effect of sharing across national EEZs. Third, we need to account for differences in species' intrinsic biological characteristics to ensure credible comparisons between fish stocks. Fourth and final, different fish stocks can be governed by one or more management programs of different types that affect their status separately from any transboundary effects. 
To address these challenges, we compile data on the abundance and biological characteristics of global fish stocks from scientific stock assessments, and combine them with data describing known fishery management programs and spatiallyexplicit species distributions. Fish stock spatial distributions are exogenous to political borders and do not require national catch statistics to determine which nations may be partial "owners" of a fish stock. To investigate fish stocks' relative abundance and biological characteristics, we utilize the RAM Legacy Stock Assessment Database, the world's most complete and scientifically robust database of fish stock status (Ricard et al., 2012). Combining these data on the population size and spatial distribution for 213 global fish stocks and 297 combinations of stock and management programs representing 47 percent of all global capture fisheries production since 1980, we build a unique global panel data set and use it to analyze whether shared fish stocks are systematically exploited to lower population levels than non-shared stocks.

\section{MATERIALS AND METHODS}

\subsection{Data}

The data we use in the analysis come from matching spatial and temporal data on fish stocks to a spatial map of global Exclusive Economic Zones (EEZs). The fisheries status data come from the RAM Legacy Stock Assessment Database v. 4.44 (Ricard et al., 2012). The RAM database compiles data from stock assessment documents that estimate annual biomass (fish population or stock size) of exploited fish stocks. These data have been used extensively in previous studies to assess the effectiveness of different types of management (Melnychuk et al., 2012); to establish the current status of fisheries around the world (Hilborn et al., 2020); and to project likely effects of future fisheries management approaches (Costello et al., 2016). Every stock assessment included in the database is submitted by the scientists or agencies that perform the assessments. Scientific stock assessments can be performed either at the national (e.g., the National Marine Fisheries Service in the United States) or international (e.g., ICES in the European Union) level. Each is quality checked by RAM database administrators. This being the case, the stock assessments represent the best scientific knowledge of the biological and exploitation status of each included stock. Although this aspect of our data means allows for rigorous statistical analysis, it likely also means that our sample is biased toward fisheries that are generally well-studied and wellmanaged, relative to fisheries that are not scientifically assessed.

Fish stock spatial distributions are adapted from Free et al. (2019), who estimated and digitized spatial boundaries of fish stocks from many of the same published stock assessments as used for our measures of stock status. We match these stock distributions to EEZs spatially, by counting the number of 1square-kilometer cells that overlap each EEZ. An example stock distribution is shown in Figure 1. The resulting proportions of stock distributions within EEZs are used to derive transboundary variables for statistical analysis (see next section).

Fishery management, although not the explicit focus of this study, is important in driving fish stock status (Melnychuk

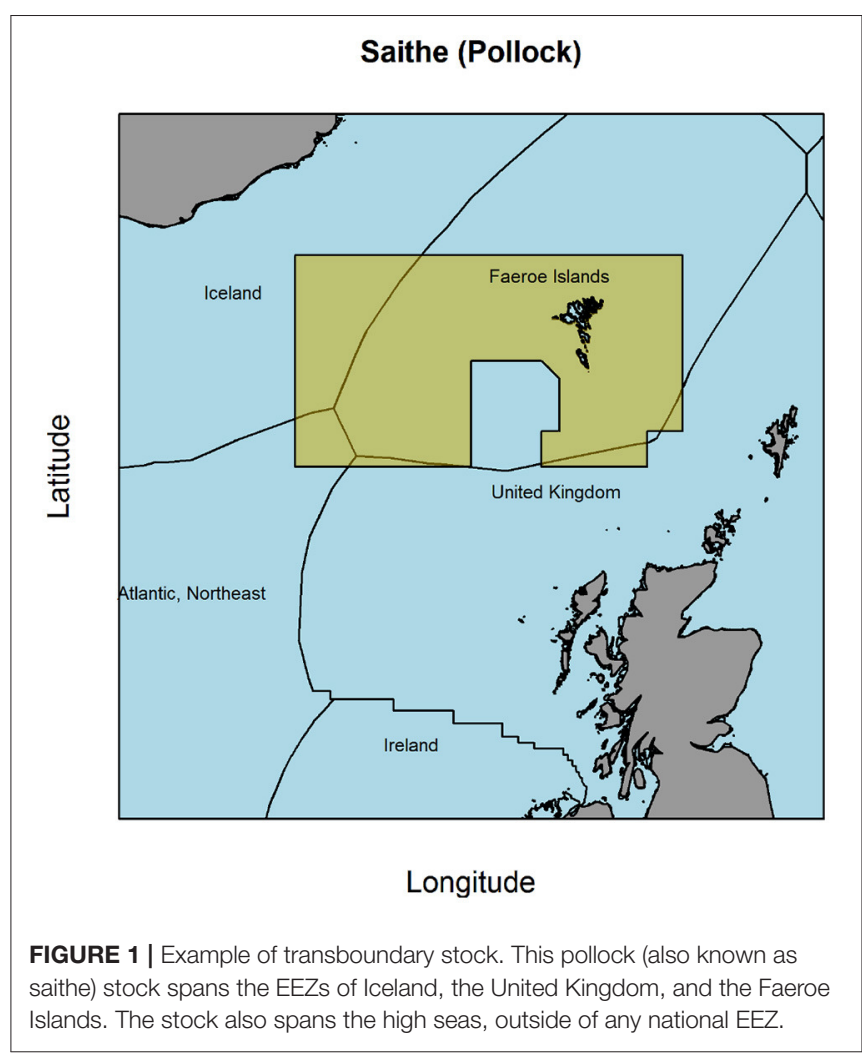

et al., 2012). To control for the effect of different fishery management programs, we restrict our panel to all fish stocks that have transitioned into one or multiple known rights-based management programs (also known as catch shares or outputbased management). Although the choice to restrict our panel in this way reduces the total number of fisheries we can analyze, it also helps to avoid the pitfall of omitted variable bias in cases where the implementation of a given management program is correlated with our variables of interest. Information on rights-based management programs is extracted from a database maintained by the Environmental Defense Fund's Fishery Solutions Center (Bonzon et al., 2010). Matching fish stocks to management programs results in some fish stocks being assigned to multiple management programs, which we treat as separate observations. The final panel contains 213 unique fish stocks and 297 unique combinations of fish stocks and management programs. Because of data limitations, for stocks managed under multiple management programs, we cannot determine with certainty the percentage of stock biomass or catches directly attributable to each individual program. Therefore, we keep each fish stock-management program combination as a separate observation.

\subsection{Spatial Thresholds}

Because we directly relate fish stock spatial distributions to EEZ borders, we have to decide what constitutes whether a country is one "owner" of a fish stock. If, for example, one percent of a fish stock's spatial range lies within a country's EEZ, does 
that imply that the country has true access to the stock, with all of its associated incentives? To tackle this ambiguity in the transboundary categorization, we use the fish stock ranges to define a minimum percentage of each stock's spatial range that must be present in an EEZ in order for that EEZ to be included as one owner of the fish stock. We construct multiple of these "spatial thresholds" from 0 to 25 percent to test the effect of this choice. Accordingly, through our spatial analysis, we are also able to distinguish between different types of stocks, including those that are non-transboundary (i.e., stocks not spanning multiple EEZs). For example, we can identify stocks that span two or more EEZs but do not span the high seas, or stocks that occur only in the high seas and not within any EEZs.

\subsection{Linear Transboundary Effect on Abundance}

The theory (see section 1 in Supplementary Material) suggests that transboundary resources will be overexploited, even in the presence of extraction agreements. To test these predictions empirically, we estimate a linear random effects model applied to the panel data set describing stock status over time for the 213 fish stocks from years 1990 to 2018 . Because some fish stocks are managed under multiple different management programs, the unit of observation is a unique fish stock-management program combination $i$, which is fished in FAO region $r$ in year $t$. The associated model is:

$$
\begin{aligned}
Y_{i r t} & =\alpha+\beta \text { SHARED }_{i}+\gamma E E Z_{i}+\delta H H I_{i} \\
& +v H S_{i}+\eta^{\prime} \Lambda_{i}+\zeta^{\prime} M G M T_{i t}+\theta^{\prime} X_{r t}+\epsilon_{i r t}
\end{aligned}
$$

$Y$ is the response variable, $B / B_{M S Y} . B / B_{M S Y}$ is the measure of fish population abundance (measured as biomass) relative to each fish stock's biomass that would give rise to maximum sustainable yield, $B_{M S Y}$. The measure of $B / B_{M S Y}$ for each stock is drawn directly from the RAM database, and is not aggregated or altered from its reported form. SHARED is a binary indicator that takes a value of one if a fish stock is shared by more than one Exclusive Economic Zone (EEZ) after the implementation of EEZs as a result of the 1982 Law of the Sea Convention. EEZ and HHI are two further measures of the extent of stock distribution across national jurisdictions. EEZ measures the total number of EEZs that a stock is distributed over and takes a value of 0 when a stock is distributed only in the high seas, outside any national jurisdiction. HHI denotes Herfindahl-Hirschman Index (HHI), and it is a measure of the relative concentration of the stock's range across its constituent EEZs. The HHI is computed on the proportions of each stock's spatial distribution captured by different EEZs. Conceptually, HHI increases with a decreasing total number of EEZs and with increased concentration of a fish stock within fewer EEZs. $\beta, \gamma$, and $\delta$ are the parameters of interest and denote the average change of status if a stock is shared, distributes over an additional jurisdiction, or becomes more concentrated in one nation, respectively. Our analysis estimates these three parameters separately.

$H S$ is a binary variable that denotes whether a meaningful proportion (defined by the spatial threshold) of the stock's distribution lies within the high seas, outside of any national
EEZ. $\Lambda_{i}$ is a vector of stock-program characteristics (i.e., species category and biological life-history parameters). MGMT is a vector of management programs categories that indicates which type of management is in place for stock-program combination $i$ at time $t$, as well as if there are multiple programs in place for that stock. $X_{r t}$ is a battery of year, FAO region, and yearly by FAO region dummies. Finally, $\epsilon$ is the error term of the model. Serial correlation is controlled for via quasi-differentiation and standard errors are clustered by FAO region to account for spatial correlation.

\subsection{Odds of Overexploitation}

In addition to the linear model described above, we also perform a panel probit analysis to test for the odds of a given stock becoming overexploited. In other words, we test the odds that relative abundance $B / B_{M S Y}$ falls below 1 (see Supplementary Material for additional thresholds). The model assumes that the individual random effect, $v_{i}$, is distributed normal $N\left(0, \sigma_{v}^{2}\right)$. Grouping the above variables into vector $Z_{i t}$ and coefficients into vector $\Theta$ :

$$
\begin{aligned}
& P\left(Y_{i 1}, \ldots, Y_{i n_{i}} \mid Z_{i 1}, \ldots, Z_{i n_{i}}\right) \\
& =\int_{-\infty}^{\infty} \frac{e^{-v_{i}^{2} / 2 \sigma_{v}^{2}}}{\sqrt{2 \pi} \sigma_{v}}\left\{\prod_{t=1}^{n_{i}} F\left(Y_{i t}, Z_{i t}^{\prime} \Theta+v_{i}\right)\right\} d v_{i}
\end{aligned}
$$

with

$$
F(y, z)= \begin{cases}\Phi(z) & \text { if } y \neq 0 \\ 1-\Phi(z) & \text { if } y=0\end{cases}
$$

where $\Phi$ is the cumulative distribution function of the standard normal. It follows then, that the likelihood function would be given by:

$$
\mathcal{L}(Y \mid X, \Theta, \sigma)=\sum_{i} \int_{-\infty}^{\infty} \frac{e^{-v_{i}^{2} / 2 \sigma_{v}^{2}}}{\sqrt{2 \pi} \sigma_{v}}\left\{\prod_{t=1}^{n_{i}} F\left(Y_{i t}, Z_{i t}^{\prime} \Theta+v_{i}\right)\right\} d v_{i}
$$

Estimated coefficients are derived from the maximization of $\mathcal{L}$ over $\Theta$ and $\sigma_{v}$. Standard errors are clustered by FAO region assuming idiosyncratic shocks are uncorrelated across clusters. We estimate the linear and panel probit models above for spatial thresholds from 0 to 25 percent. Note that the choice of threshold affects the calculation of SHARED, EEZ, HHI, and HS in Equations (1) and (4).

\subsection{Distribution of Transboundary Fisheries}

We use all documented fish stock distributions (Free et al., 2019) (comprising 780 stocks), not just those that match known fishery management programs, to map the prevalance of transboundary stocks across regions of the global oceans. To obtain proportional prevalence of transboundary stocks for each region, we divide the number of stocks that span two or more EEZs by the total number of stocks spanning that region. From this denominator, we exclude stocks that are exclusively contained within the high seas. 
Additionally, we use estimates of the transboundary effect from our statistical models to calculate the total effect of the transboundary problem on fish abundance for the fisheries in our analysis. Keeping all control variables constant and using spatial thresholds of 10 and 15 percent, we estimate the difference between the status quo and a theoretical setting where all stocks are non-shared (applying estimates from specification 8 in Supplementary Table 6). In simple terms, we calculate the difference in the total abundance of the fish stocks in our analysis between worlds with and without the transboundary problem.

\section{RESULTS}

We find robust and statistically significant evidence that fish stocks spanning multiple EEZs have lower relative abundance than those contained within single EEZs. Compared to nonshared stocks, transboundary fish stocks have on average lower relative abundance $\left(B / B_{M S Y}\right)$ and are more likely to be exploited beyond their maximum sustainable yield, which we refer to as “overexploited" (Figure 2).

Fish stocks shared across multiple EEZs have, on average, a lower $B / B_{M S Y}$ than those contained in a single jurisdiction at any given point in time (Figure $2 \mathrm{~A}$ ). Specifically, regression estimates indicate that the $B / B_{M S Y}$ of a transboundary stock is, in average, between 0.26 to 0.48 lower than a non-transboundary stock, after controlling for management, location, year and species' characteristics. These results are consistent at spatial thresholds greater than 5 percent. Furthermore, each additional EEZ has increasingly detrimental effects on the expected abundance of a stock (Figure 2B).

The spatial distribution of a fish stock's range across its containing EEZs also affects its abundance. The HerfindahlHirschman Index is commonly used as a metric to describe market concentration, and in our formulation it measures the concentration of each fish stock's range across EEZs. The HHI metric is greater when a stock is contained within fewer EEZs, or when a stock's range is unevenly distributed across EEZs (i.e., more concentrated). We find that a greater $\mathrm{HHI}$ counteracts the negative transboundary effect (Figure 2C). That is, more concentrated stocks exhibit greater abundance (on average) than stocks that are more evenly distributed across the same number of EEZs.

Overall, our results for transboundary effects on abundance are consistent at spatial thresholds greater than 5 percent. By varying the threshold, we investigate the sensitivity of transboundary effects to our definition of sharing. Because the threshold determines the proportion of a stock's range that must be present in an EEZ for that EEZ to be considered a fish stock owner, changing the threshold affects which stocks are classified as shared and alters the number of owners of each stock (see Supplementary Material). Our estimates are most consistent under spatial thresholds of 10, 15, and 20 percent. It is also worth noting that a majority of our transboundary stocks for thresholds above 5 percent come from the Northeast Atlantic region. This pattern could create problems in inference if this regional balance is not controlled for, thus our choice to explicitly include spatial controls and account for spatial correlation.

Along with having a lower relative abundance, transboundary stocks are more likely to be overexploited (Figures 2D-F). However, this result is less consistent across thresholds. The changes in the predicted probit index shown in Figures 2D-F reveal that for spatial thresholds between 10 and 20 percent, shared stocks and stocks spanning additional EEZs are more likely to be overexploited $\left(B / B_{M S Y}<1\right)$ compared to nonshared stocks. For other thresholds and for the effect of HHI, the transboundary effect on the odds of overexploitation is indistinguishable from zero. Although the point estimates for the effect of HHI are predominantly negative-a direction that would be consistent with results from the abundance regressionthe data lack sufficient variation to more precisely identify an effect. Additional results for more severe definitions of overexploited $\left(B / B_{M S Y}<0.8\right.$ and $\left.B / B_{M S Y}<0.6\right)$ are available in the Supplementary Material. These results are consistent with the results for abundance, and indicate that sharing increases the likelihood of overexploitation, while increased stock concentration (HHI) decreases that likelihood. The results of both types of statistical models are robust to many specifications, including the inclusion or exclusion of fixed effects for species life-history traits, world (FAO) region, and type of management (see Supplementary Material).

Utilizing the full dataset of 780 stock spatial distributions to calculate the proportion of fish stocks that are transboundary across world regions, we find that the transboundary burden is greater in some regions than others (Figure 3). Some regions have a low proportional burden of transboundary stocks, such as North America, where large fishing nations like Canada and the United States control enormous national EEZs. However, some regions are at much greater risk of negative transboundary effects, most notably in Europe and the eastern Atlantic.

We also calculate the total global burden of the transboundary problem, using the estimates of the transboundary effect from a model that includes all biological, regional, and management controls. Averaging across the most recent 10 years for each fish stock, we find that wasted biomass due to the transboundary effect amounts to approximately 4-17 million metric tons (MMT) annually in decreased biomass relative to a setting where no fisheries are transboundary. This result is driven in part by large, transboundary European fish stocks, with 10 stocks accounting for approximately 95 percent of the estimated gain. Notably, because we only have stock status and transboundary information for a subset of fish populations, this estimate is only for the fisheries in our regression analyses, a sample comprising about half of all globally-reported fisheries landings (FAO, 2020).

\section{DISCUSSION}

A main goal of both fisheries management and marine conservation is to ensure the resilience of marine ecosystems and the sustainability of marine resources for the benefit of future generations. Extensive exploitation of valuable species is a phenomenon driven by complex linkages between ecological 

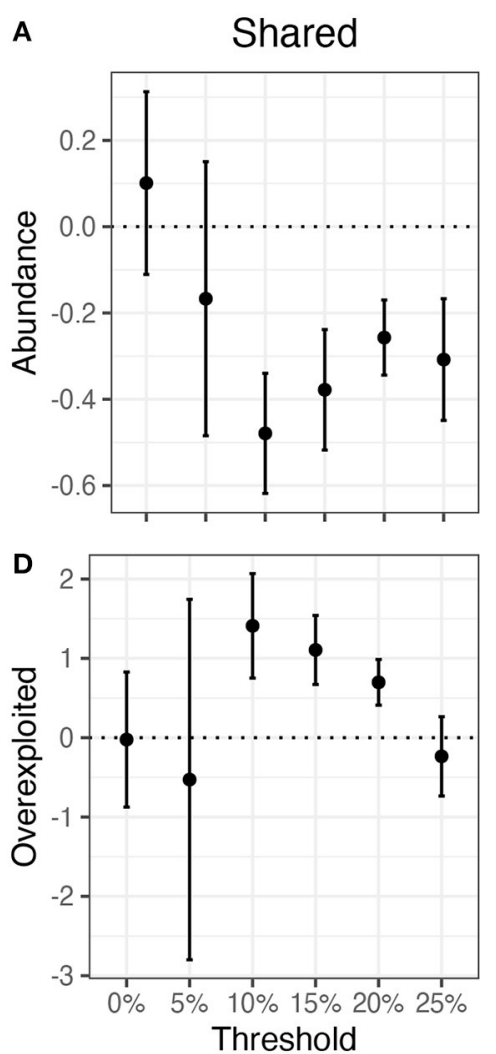

B

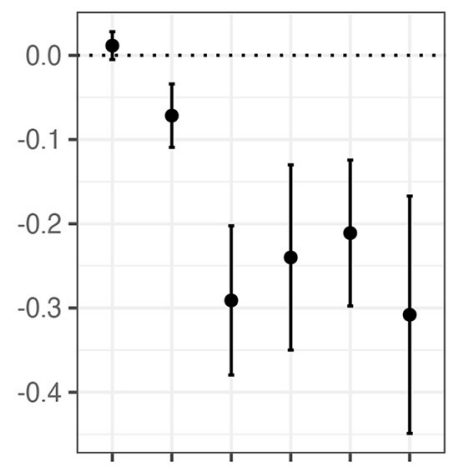

E

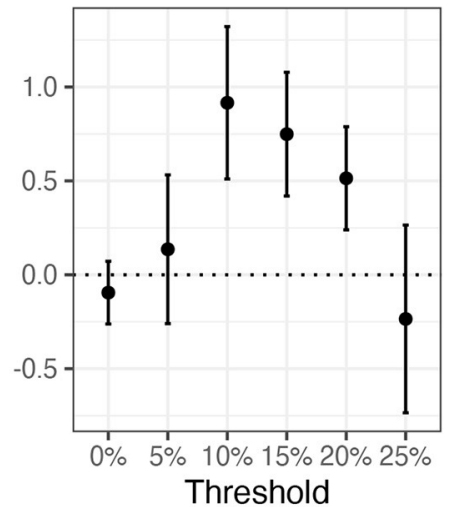

c

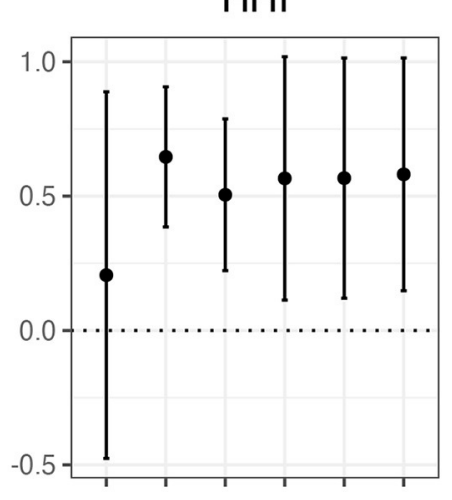

F

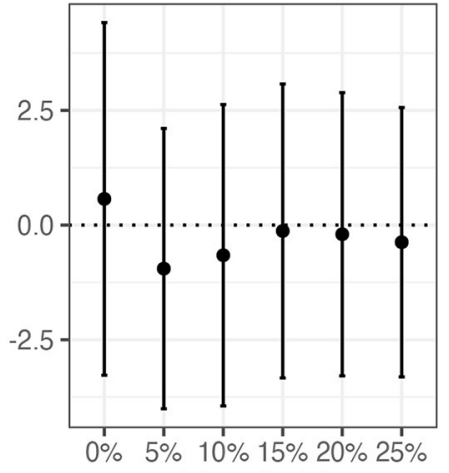

Threshold

FIGURE 2 | Estimates of the transboundary problem in marine fisheries. All plots show the estimates as a function of the minimum threshold percentage of a stock's spatial distribution that must be present in each containing EEZ. The top row $(\mathbf{A}-\mathbf{C})$ shows the linear regression estimates on abundance, measured as $B / B_{M S Y}$, while the bottom row shows the standard deviation change in the predicted probit index on the odds of a stock being overexploited, measured as $B / B_{M S Y}<1$. Columns show effects of a stock being contained in at least 2 EEZs (A,D), the effect of each additional EEZ (B,E), and the effect of the stock's relative spatial concentration across EEZs (C,F). Note varying y-axis scales.

and human behavioral dynamics. In recent decades, though, overfishing in particular has been recognized and tackled with effective management tools on the national scale in many nations (Hilborn et al., 2020). However, our results suggest that the enclosure of ocean regions via the establishment of EEZs is not absent of complications, and could create competitive incentives that result in another pernicious effect: the transboundary problem.

When fish stocks are distributed across multiple national EEZs, competitive access creates incentives for over-extraction, leading to lower relative abundance. Furthermore, expected fish stock abundance declines-and likelihood of overexploitation increases-progressively with every additional EEZ the stock spans. In sum, the establishment of EEZs defines national property rights governing the extraction of resources from the ocean, but resources whose natural distributions cross EEZs are still subject to competition between nations and are at additional risk of overexploitation. We estimate that the total annual biomass loss to this sort of effect, across the fisheries examined in the study, is between 4 and 17 MMT. This effect persists despite the presence of scientific stock assessments and rights-based fisheries management in the fisheries we studied.
Note, however, that our estimate only encompasses a subset of all global fisheries, and as such is a rough approximation of a dynamic phenomenon. Nevertheless, placed in context, our estimate ranges between values equal to the total annual marine harvests of the United States (4.72 MMT) and China (12.7 MMT), who rank sixth and first, respectively, among all nations in fisheries production (FAO, 2020).

Recent research (Melnychuk et al., 2012, 2017) has shown clearly that scientific stock assessment and strong fisheries management controls-including rights-based managementaffect the biological status of fish stocks. In general, assessed fisheries with intensive management are at or near target biomass levels (Hilborn et al., 2020). Since we include in our analysis only these type of stocks, it is likely that our results are conservative. That is, our estimates represent a lower bound on the extent and magnitude of the global transboundary fisheries problem, and the inefficiencies we identify are only expected to be worse for unassessed or unmanaged fisheries spanning multiple jurisdictions.

Although our analysis is global in scale, clearly not all transboundary fisheries situations are equivalent. To the extent possible, we queried a range of definitions of "transboundary" in 


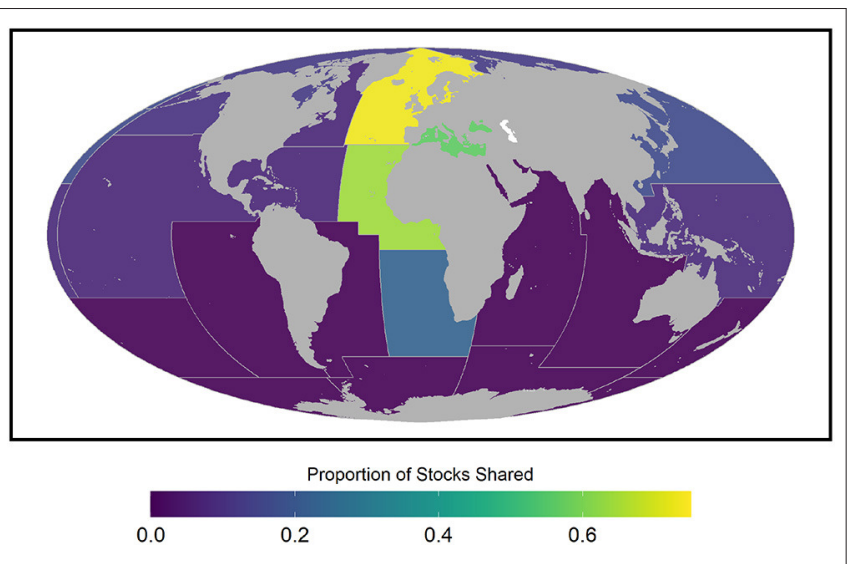

FIGURE 3 | Proportion of transboundary species within major Food and Agriculture Organization fishing regions. Proportions are calculated among 780 fish stocks with known spatial distributions, including stocks that have spatial distribution information but not enough data for the full panel regressions. A threshold of 10 percent is used to designate transboundary stocks.

our analyses, including varying the spatial threshold required for stock ownership and investigating the effect of multiple measures of transboundary: binary sharing (i.e., is a resource shared or not), total number of EEZs, and relative stock concentration across EEZs. Although the significance of the transboundary effect is consistent across most model specifications, our results also highlight important nuances that should be incorporated in any future studies on transboundary effects. For example, one key choice and contribution of our study is to allow the spatial threshold required for stock ownership to vary. In practice, defining transboundary fisheries using a very low threshold means that a large number of stocks are categorized as shared, but at the same time the proportion of the stock spanning a second or third EEZ may be extremely small (e.g., 0 to 5 percent of its range). The competition effect in such cases may be minimal, as stocks marginally overlapping additional EEZs would be classified as shared but may perform as if they were completely enclosed in just a single EEZ. Consequently, the degree and nature of shared ownership matters at least as much as the binary condition of whether or not a resource is shared. Our estimates for the effect of relative stock concentration (HHI) support this conclusion as well-fish stocks spanning the same number of EEZs, but concentrated among those EEZs differently, have different expected outcomes.

Tackling the transboundary problem from a management perspective will require honest policymaking on an international scale. The management of transboundary fisheries is likely hindered by complex sociopolitical considerations such as national sovereignty and culture, the cost of negotiation, and the burden of enforcement. While we identified the magnitude of the transboundary effect in many global fisheries, these barriers to effective management are important avenues for further interdisciplinary research. Although our sample is biased toward large, scientifically assessed fisheries, we found that, in our sample, Europe and other parts of the eastern Atlantic are predominant regions for transboundary fisheries. These are regions where intensive institutional endeavors to coordinate fisheries management (e.g., the Common Fisheries Policy in Europe) have continued to struggle to achieve sustainable fisheries management (Brooks et al., 2016; Belschner et al., 2019). While these sorts of institutions are required to guide the development of transboundary harvest policies, we have shown that solving the transboundary problem is not trivialindeed, the transboundary effect persists even among the world's best-studied and best-managed fisheries.

These results are concerning, but progress has been made and successes have occurred in some fisheries. For instance, the Northeast Arctic cod stock has been rebuilt by the joint efforts of Norway and Russia (ICES HQ, 2016). Elsewhere, although tuna Regional Fisheries Management Organizations continue to wrestle with issues around national sovereignty, equity, and scientifically-based allocation decisions (Seto et al., 2021), many highly migratory tuna stocks are harvested at sustainable levels (ISSF, 2020). These fisheries, however, remain the exception rather than the rule. Furthermore, with climate change likely to alter the distributions (and consequently, the owners) of fish stocks (Pinsky et al., 2013), international policies will become increasingly critical for appropriately managing shared marine resources (Gaines et al., 2018).

Finally, the oceans are certainly not the only place where the transboundary problem exists, or where it will continue to arise, and our analysis provides important general insights for shared resources. Biodiversity conservation, the conservation of wide-ranging birds (Wolf et al., 2006; Yong et al., 2018), and international river management (Zeitoun et al., 2013) are all endeavors that struggle with the same transboundary challenges as marine fisheries. More than one third of high-biodiversity terrestrial sites span international borders, and the issues with transboundary resources can pose severe implications for the conservation of forests and sensitive megafauna. Just as importantly, the United Nations estimates that more than 140 nations share common lake and river basins, and that 300 transboundary aquifers helping serve two billion people are currently classified as internationally shared groundwater access (UN Water, 2008; Vasilijević et al., 2015). Across the world, transboundary resource management is hindered by institutional and political challenges, including balancing national self-interest with overall resource sustainability and appropriately empowering multilateral management bodies. In an increasingly resource-stressed world, a key direction for future research is to combine an understanding of the dynamics of transboundary natural resources with the implications of the transboundary problem for equity and development.

Our analysis describes the outcomes when marine resources are shared across international boundaries. We provide evidence that internationally shared fish stocks are systematically more likely to be overexploited and have lower relative abundance than resources solely owned by one nation. Solving the transboundary problem in natural resource management, whether it be in the oceans or on land, will require careful international governance solutions. 


\section{DATA AVAILABILITY STATEMENT}

The datasets presented in this study can be found in online repositories. The names of the repository/repositories and accession number(s) can be found below: https://github.com/ owenrliu/transboundary_fisheries_status.

\section{AUTHOR CONTRIBUTIONS}

All authors listed have made a substantial, direct and intellectual contribution to the work, and approved it for publication.

\section{ACKNOWLEDGMENTS}

We would like to thank Christopher Costello, David Kelly, Corbett Grainger, Dan Ovando, and Cody Szuwalski for

\section{REFERENCES}

Agrawal, A. (2001). Common property institutions and sustainable governance of resources. World Dev. 29, 1649-1672. doi: 10.1016/S0305-750X(01)00063-8

Bailey, M., Sumaila, U. R., and Lindroos, M. (2010). Application of game theory to fisheries over three decades. Fish. Res. 102, 1-8. doi: 10.1016/j.fishres.2009.11.003

Barrett, S. (2003). Environment and Statecraft: The Strategy of Environmental Treaty-Making: The Strategy of Environmental Treaty-Making. Oxford: Oxford University Press.

Belschner, T., Ferretti, J., Strehlow, H., Kraak, S. B., Döring, R., Kraus, G., et al. (2019). Evaluating fisheries systems: a comprehensive analytical framework and its application to the EU's common fisheries policy. Fish Fish. 20, 97-109. doi: 10.1111/faf.12325

Bonzon, K., McIlwain, K., Strauss, C. K., and Van Leuvan, T. (2010). Catch Share Design Manual: A Guide for Managers and Fishermen. Environmental Defense Fund.

Brooks, C. M., Crowder, L. B., Curran, L. M., Dunbar, R. B., Ainley, D. G., Dodds, K. J., et al. (2016). Science-based management in decline in the southern ocean. Science 354, 185-187. doi: 10.1126/science.aah4119

Cheung, W. W., Pinnegar, J., Merino, G., Jones, M. C., and Barange, M. (2012). Review of climate change impacts on marine fisheries in the uk and ireland. Aquat. Conserv. Mar. Freshw. Ecosyst. 22, 368-388. doi: 10.1002/aqc.2248

Christy, F. T. (1982). Territorial Use Rights in Marine Fisheries: Definitions and Conditions, Vol. 227. Rome: Food \& Agriculture Organization.

Costello, C., and Molina, R. (2021). Transboundary marine protected areas. Resour. Energy Econ. 65:101239. doi: 10.1016/j.reseneeco.2021.101239

Costello, C., Ovando, D., Clavelle, T., Strauss, C. K., Hilborn, R., Melnychuk, M. C., et al. (2016). Global fishery prospects under contrasting management regimes. Proc. Natl. Acad. Sci. U.S.A. 113, 5125-5129. doi: 10.1073/pnas.1520420113

Cullis-Suzuki, S., and Pauly, D. (2010). Failing the high seas: a global evaluation of regional fisheries management organizations. Marine Policy 34, 1036-1042. doi: 10.1016/j.marpol.2010.03.002

FAO (2020). The State of World Fisheries and Aquaculture 2020. Sustainability in Action. Food and Agriculture Organization of the United Nations.

Free, C. M., Thorson, J. T., Pinsky, M. L., Oken, K. L., Wiedenmann, J., and Jensen, O. P. (2019). Impacts of historical warming on marine fisheries production. Science 363, 979-983. doi: 10.1126/science.aau1758

Gaines, S. D., Costello, C., Owashi, B., Mangin, T., Bone, J., Molinos, J. G., et al. (2018). Improved fisheries management could offset many negative effects of climate change. Sci. Adv. 4:eaao1378. doi: 10.1126/sciadv.aao1378

Hannesson, R. (2011). Game theory and fisheries. Annu. Rev. Resour. Econ. 3, 181-202. doi: 10.1146/annurev-resource-083110-120107

Hardin, G. (2009). The tragedy of the commons. J. Nat. Resour. Policy Res. 1, 243-253. doi: 10.1080/19390450903037302 useful comments in the early stages of this paper. We would also like to thank Sabrina Eisenbarth and attendants to Fisheries Session sponsored by the National Oceanographic and Atmospheric Administration at the Association of Environmental and Resource Economists summer meeting in Tahoe City, California. We are thankful to the Fisheries Solutions Center at the Environmental Defense Fund, particularly Jeff Young, for access to their panel on fisheries management programs.

\section{SUPPLEMENTARY MATERIAL}

The Supplementary Material for this article can be found online at: https://www.frontiersin.org/articles/10.3389/fmars. 2021.656023/full\#supplementary-material
Hilborn, R., Amoroso, R. O., Anderson, C. M., Baum, J. K., Branch, T. A., Costello, C., et al. (2020). Effective fisheries management instrumental in improving fish stock status. Proc. Natl. Acad. Sci. U.S.A. doi: 10.1073/pnas.1909726116

ICES HQ, C. (2016). Report of the Arctic Fisheries Working Group (AFWG). Technical report, The International Council for the Exploration of the Sea.

ISSF (2020). Status of the World Fisheries for Tuna. Technical report. International Seafood Sustainability Foundation, Washington, DC.

Katerere, Y., Hill, R., and Moyo, S. (2001). A Critique of Transboundary Natural Resource Management in Southern Africa. IUCN, Regional Office for Southern Africa Harare.

Kliot, N., Shmueli, D., and Shamir, U. (2001). Institutions for management of transboundary water resources: their nature, characteristics and shortcomings. Water Policy 3, 229-255. doi: 10.1016/S1366-7017(01)00008-3

Lysenko, I., Besançon, C., and Savy, C. (2007). UNEP-WCMC Global List of Transboundary Protected Areas. UNEP and the World Conservation Monitoring Center, Cambridge.

Mackelworth, P. (2012). Peace parks and transboundary initiatives: implications for marine conservation and spatial planning. Conserv. Lett. 5, 90-98. doi: 10.1111/j.1755-263X.2012.00223.x

Maurihungirire, M. (2008). "Transboundary issues in the purse-seine, trawl and crustacean fisheries of the Southeast Atlantic," in Management of Shared Fish Stocks, eds A. I. L. Payne, C. M. O’Brien, and S. I. Rogers (Oxford: Blackwell), 151-164.

McWhinnie, S. F. (2009). The tragedy of the commons in international fisheries: an empirical examination. J. Environ. Econ. Manage. 57, 321-333. doi: 10.1016/j.jeem.2008.07.008

Melnychuk, M. C., Essington, T. E., Branch, T. A., Heppell, S. S., Jensen, O. P., Link, J. S., et al. (2012). Can catch share fisheries better track management targets? Fish Fish. 13, 267-290. doi: 10.1111/j.1467-2979.2011. 00429.x

Melnychuk, M. C., Peterson, E., Elliott, M., and Hilborn, R. (2017). Fisheries management impacts on target species status. Proc. Natl. Acad. Sci. U.S.A. 114, 178-183. doi: 10.1073/pnas.1609915114

Munro, G. R. (1990). The optimal management of transboundary fisheries: game theoretic considerations. Nat. Resour. Model. 4, 403-426. doi: 10.1111/j.1939-7445.1990.tb00218.x

Munro, G. R. (2010). The 1982 UN Convention on the Law of the Sea and Beyond: The Next 25 Years. Handbook of Marine Fisheries Conservation and Management.

Nordquist, M. (2011). United Nations Convention on the Law of the Sea 1982, Volume VII: A Commentary. Leiden: Brill. doi: 10.1163/ej.9789004191174.iii-488

Palacios-Abrantes, J., Reygondeau, G., Wabnitz, C. C., and Cheung, W. W. (2020). The transboundary nature of the world's exploited marine species. Sci. Rep. 10, 1-12. doi: 10.1038/s41598-020-74644-2 
Pinsky, M. L., Reygondeau, G., Caddell, R., Palacios-Abrantes, J., Spijkers, J., and Cheung, W. W. (2018). Preparing ocean governance for species on the move. Science 360, 1189-1191. doi: 10.1126/science.aat2360

Pinsky, M. L., Worm, B., Fogarty, M. J., Sarmiento, J. L., and Levin, S. A. (2013). Marine taxa track local climate velocities. Science 341, 1239-1242. doi: 10.1126/science. 1239352

Pons, M., Melnychuk, M. C., and Hilborn, R. (2018). Management effectiveness of large pelagic fisheries in the high seas. Fish Fish. 19, 260-270. doi: $10.1111 /$ faf.12253

Poore, D. (2003). Changing Landscapes: The Development of the International Tropical Timber Organization and Its Influence on Tropical Forest Management. London: Earthscan Publications.

Ricard, D., Minto, C., Jensen, O. P., and Baum, J. K. (2012). Examining the knowledge base and status of commercially exploited marine species with the ram legacy stock assessment database. Fish Fish. 13, 380-398. doi: $10.1111 / j .1467-2979.2011 .00435 . x$

Sanchez, J. C., and Roberts, J. (2014). Transboundary Water Governance: Adaptation to Climate Change. IUCN.

Schaefer, A. (1995). 1995 Canada-Spain fishing dispute (the Turbot War). Geo. Intl. Environ. Rev. 8:437.

Schiffman, H. S., and MacPhee, B. P. (2014). The southern bluefin tuna dispute revisited: how far have we come? Transnat. Environ. Law 3, 391-406. doi: $10.1017 /$ S2047102514000119

Seto, K., Galland, G. R., McDonald, A., Abolhassani, A., Azmi, K., Sinan, H., et al. (2021). Resource allocation in transboundary tuna fisheries: a global analysis. Ambio 50, 242-259. doi: 10.1007/s13280-020-01 371-3

Teh, L. S., and Sumaila, U. R. (2015). Trends in global shared fisheries. Mar. Ecol. Prog. Ser. 530, 243-254. doi: 10.3354/meps 11049

Timothy, D. J. (1999). Cross-border partnership in tourism resource management: international parks along the us-canada border. J. Sustain. Tourism 7, 182-205. doi: $10.1080 / 09669589908667336$
UN Water (2008). "Transboundary waters: sharing benefits, sharing responsibilities," in Thematic Paper (Geneva), 20.

Vasilijević, M., Zunckel, K., McKinney, M., Erg, B., Schoon, M., and Rosen Michel, T. (2015). Transboundary Conservation: A Systematic and Integrated Approach. Best Practice Protected Area Guidelines Series No. 23, IUCN, Gland, xii+107.

Wolf, S., Keitt, B., Aguirre-Munoz, A., Tershy, B., Palacios, E., and Croll, D. (2006). Transboundary seabird conservation in an important north American marine ecoregion. Environ. Conserv. 33, 294-305. doi: 10.1017/S0376892906003353

Yong, D. L., Jain, A., Liu, Y., Iqbal, M., Choi, C.-Y., Crockford, N. J., et al. (2018). Challenges and opportunities for transboundary conservation of migratory birds in the east Asian-Australasian flyway. Conserv. Biol. 32, 740-743. doi: $10.1111 /$ cobi.13041

Zeitoun, M., Goulden, M., and Tickner, D. (2013). Current and future challenges facing transboundary river basin management. Wiley Interdiscipl. Rev. Clim. Change 4, 331-349. doi: 10.1002/wcc.228

Conflict of Interest: The authors declare that the research was conducted in the absence of any commercial or financial relationships that could be construed as a potential conflict of interest.

Publisher's Note: All claims expressed in this article are solely those of the authors and do not necessarily represent those of their affiliated organizations, or those of the publisher, the editors and the reviewers. Any product that may be evaluated in this article, or claim that may be made by its manufacturer, is not guaranteed or endorsed by the publisher.

Copyright $\odot 2021$ Liu and Molina. This is an open-access article distributed under the terms of the Creative Commons Attribution License (CC BY). The use, distribution or reproduction in other forums is permitted, provided the original author(s) and the copyright owner(s) are credited and that the original publication in this journal is cited, in accordance with accepted academic practice. No use, distribution or reproduction is permitted which does not comply with these terms. 